\title{
ASCERTAINMENT AND PREVENTION IN THE ROYAL AIR FORCE
}

\author{
AIR VICE MARSHAL H B KELLY, MVO, QHS, MD, FRCP
}

All aircrew are required to have routine medical examinations throughout their professional careers every six months or so, and electrocardiograms are included on occasions, increasing in frequency with age (Table IV).

Table IV

Frequency of routine ECGs

Professional pilots and air trafiic controllers (ATCOs)

\begin{tabular}{ccccc}
\hline \multicolumn{4}{c}{ At Initial Examination and then } \\
\hline Under 30 years & -5 yearly & Over 50 years & Pilots & -6 monthly \\
$30-39$ years & -2 yearly & & & \\
$40-49$ years & - yearly & & ATCOs & - yearly \\
\hline
\end{tabular}

The examinations are useful as much for the opportunity to educate as for the detection of abnormalities. They appear to be effective as some surveys have shown that pilots have a lower incidence of coronary heart disease than others. Table $\mathrm{V}$ shows a comparison between the incidence of coronary disease in professional pilots of the American Airline Pilots' Association and the Framingham survey.

Table V

Age specific incidence of coronary disease per 1000 persons

\begin{tabular}{cccc}
\hline Age (years) & Framingham & ALPA & Framingham/ALPA \\
\hline $29-34$ & 2.93 & 0.151 & 19.4 \\
$35-39$ & 2.44 & 0.678 & 3.6 \\
$40-44$ & 5.16 & 2.050 & 2.5 \\
$45-49$ & 7.23 & 4.460 & 1.6 \\
$50-54$ & 12.70 & 8.740 & 1.5 \\
$55-59$ & 19.80 & 15.900 & 1.2 \\
\hline
\end{tabular}

In the context of coronary artery disease particular attention is paid to the presence or absence of symptoms, the height of the BP and the electrocardiogram. These have to be set into the background of possibly relevant risk factors such as smoking habit, family history, exercise etc. There may seem to be a certain amount of illogicality in the weighting given to these various aspects. Although aircrew are encouraged not to smoke, they are not grounded if they do, or if they have a bad family history and so on, but a great deal of notice is taken of an abnormal ECG, and this aspect of an airman's life often plays a very dominant role, possibly too dominant. Routine electrocardiograms are an inade- 
quate prognostic tool when dealing with individuals as opposed to populations. Nevertheless, their importance in licence loss is indicated in Table VI in which

Table VI

Loss of civil professional aircrew licence

United Kingdom September 1974 - December 1977

\begin{tabular}{lccc}
\hline & Cause & Number & Percentage \\
\hline Cardiovascular & Routine examination & 64 & 41.6 \\
& (mainly ECG) & 23 & 14.9 \\
Other & Symptomatic & 67 & 43.5 \\
\hline Total & & 154 & 100.0 \\
\hline
\end{tabular}

it can be seen that routine examination (and this most commonly means ECG) accounted for nearly three times as many losses of licence for cardiovascular reasons as spontaneous (ie symptomatic) presentation, and just under half the total licence loss.

We are surprisingly short of useful information about the ECG appearances to be expected in the young to middle-aged, and their relationship to prognosis. It is extremely common to see abnormal $T$ waves in the routine ECGs of young men in the second, third and fourth decades, and this has been a matter of great interest to us. One of the more useful studies is the 1000 Aviator Study of the US Navy in which a cohort of 1056 young aircrew aged about 24 in 1940 were investigated ${ }^{3}$. Survivors were re-examined in 1951, 1957, 1963 and 1969. One of the most important observations to be made was that gross electrocardiographic abnormalities in young, asymptomatic individuals, normal on examination, were not associated with significant morbidity or mortality. It must be accepted that this becomes increasingly less true the older the individual becomes. A survey of 13,294 routine ECGs of RAF aircrew is shown in Table VII.

Table VII

13,294 RAF aircrew ECGs 1972-1975

\begin{tabular}{lclr}
\hline & Percentage & Percentage \\
\hline Arrythmias & 0.7 & "Myocarditis" & 0.1 \\
Complete bundle branch block & & Left axis deviation beyond-30 & 0.7 \\
$\quad$ (L and R) & 0.4 & Miscellaneous & 0.6 \\
Incomplete right bundle branch block & 1.8 & ST and T changes & 3.1 \\
Heart block & 0.1 & Normal & 92.2 \\
Wolff-Parkinson-White & 0.1 & & 100.0 \\
Proven coronary disease & 0.2 & Total & \\
\hline
\end{tabular}

It will be seen that abnormalities of repolarisation constituted some 3 per cent of the whole. We have investigated a considerable number of individuals with such abnormalities in depth including coronary arteriography, echocardiography, and so on, and in the vast majority all the findings were negative except 
that the findings could be reproduced by adrenaline infusion, right atrial pacing, and most particularly by combining the two. These changes could be prevented by beta-blockade. This serves to illustrate the sort of problem to be faced in trying to eliminate from an asymptomatic aircrew population those who may constitute a threat to flight safety on account of a suspicion of coronary or other heart disease. Where symptoms occur, or when there has been a coronary attack, the answer is easy, but in the apparently fit, asymptomatic individual, one is on a hiding for nothing. There are approximately 10,000 professional civil pilots in this country, and each year let us say 20-30 are eliminated because they are thought to be too much at risk. One certainly cannot guarantee that the 9,980 left behind will remain fit, or indeed that all those grounded will have coronary attacks. Indeed there will certainly be a greater absolute number of such incidents in the remaining supposedly healthy group than in those eliminated.

How, therefore, can matters be improved? The use of the ECG exercise test is possibly one way, and in some instances it is used routinely. This is not, thankfully, our custom in this country. Some years ago, the Federal Aviation Administration of the USA proposed its routine introduction, but the Airline Pilots' Association protested to the extent of threatening to withdraw their labour should this happen. The matter was dropped, and this was quite right. It has to be accepted that in the asymptomatic population it is a test of poor specificity and poor sensitivity. It is difficult to give figures for these as it depends on the population being tested, the amount of exercise involved, and the criteria for a positive test. If it were routinely used, a considerable number of pilots would have to be investigated including coronary arteriography and doubtless many more would be grounded, possibly unnecessarily, than now. Some recent work by Marcomichelakis and his colleagues at The Middlesex Hospital indicates the possibility that the specificity of exercise ECG testing may be improved virtually to 100 per cent by retesting those with a positive ECG exercise test (however defined) after beta-blockade (oxprenolol $80 \mathrm{mg}$ ).

The ultimate criterion as to whether coronary artery disease is present or not in the asymptomatic individual must be coronary arteriography, and the extent to which this is done in these circumstances varies from country to country. In the USA and Canada it is certainly performed much more commonly than over here, but we nevertheless have to concede that often the only way to resolve the problem is to obtain the definitive answer that only it, in vivo, can give. Radionuclide investigations are often done, but are not wholly accepted as the sole determinant.

In conclusion, it will be seen that a reasonable balance has to be maintained between excessive grounding (the only totally safe way is to ground everyone) and undue leniency. In every case, it is a combination of circumstances which will decide matters rather than one isolated aspect. It is increasingly important, particularly in civil aviation, though of course the same must apply where possible in Service flying, that flight deck drill, cockpit procedures, and aircraft capabilities are such that incapacitation of a pilot matters as little as possible, or not at all. 